\title{
La fórmula estimulación/recompensa en el derecho administrativo ambiental. \\ Visión desde la administración estratégica por los sujetos de gestión The Formulate Stimulation Rewards in the Administrative Environmental Right. Vision from the Strategic Administration for the Subjects of Step
}

Alcides Antúnez Sánchez*

DOI: http://dx.doi.org/10.21503/lex.v16i21.1554

* Licenciado en Ciencias Penales y Ciencias Jurídicas. Magíster en Asesoría Jurídica. Profesor auxiliar de Derecho Ambiental e Internacional. Imparte las materias de Derecho Ambiental e Internacional Público en el Departamento de Derecho, Facultad de Ciencias Económicas y Sociales de la Universidad de Granma, República de Cuba. Email: aantunez@udg.co.cu, antunez63@nauta.cu, antunez1963@gmail.com

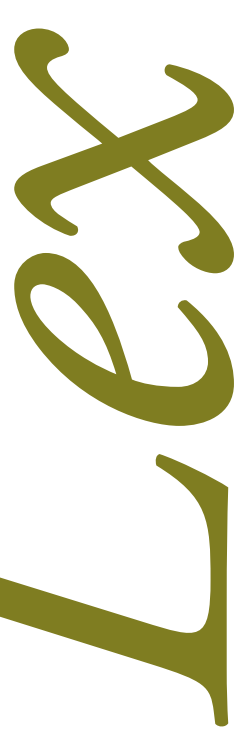




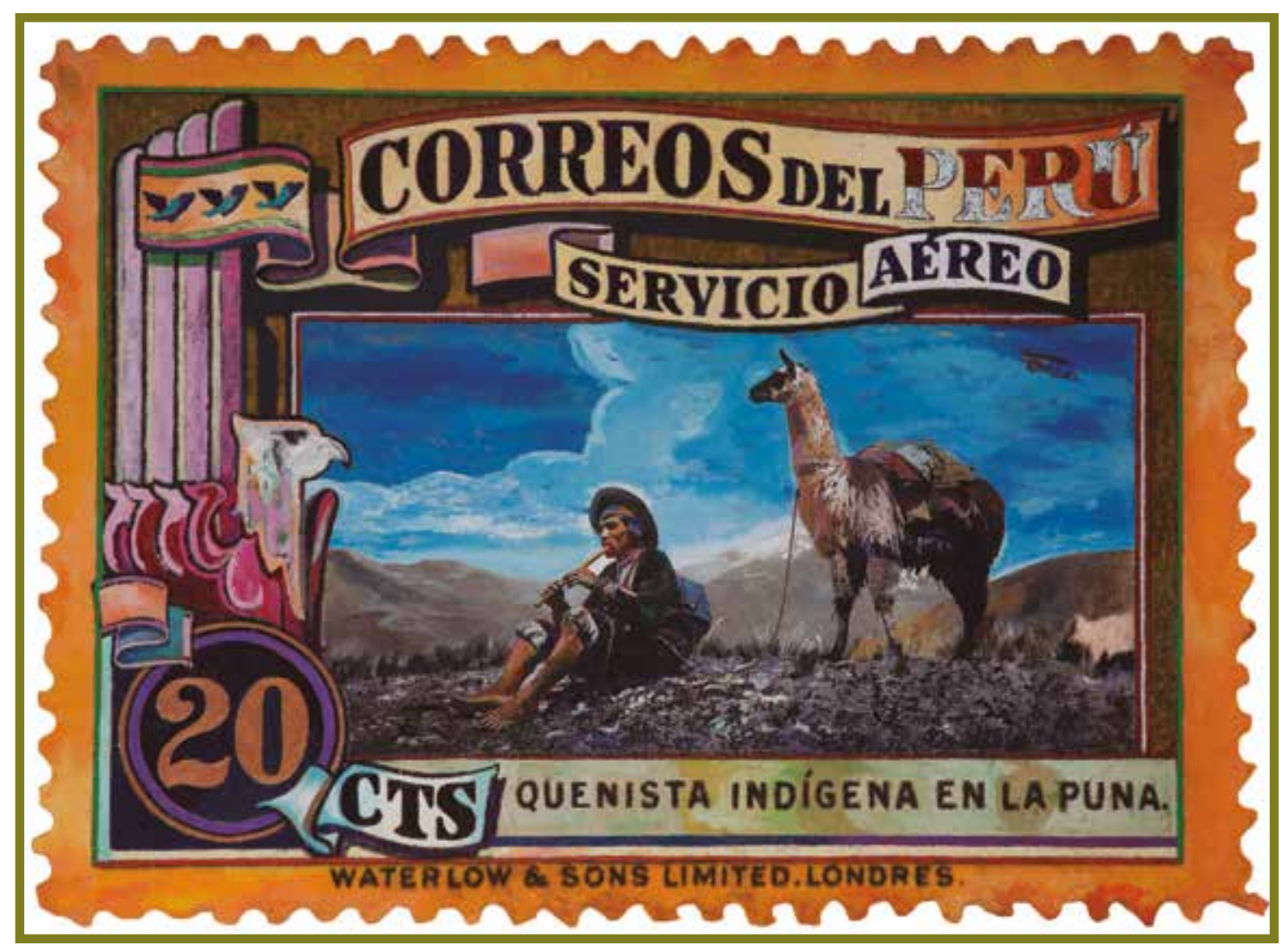

Estampilla 1936. Enrique Polanco.

https://www.facebook.com/enriquepolancopintor/ 


\section{RESUMEN}

El ensayo propone una mirada a la Administración Estratégica, donde su adecuada implementación y aplicación por los empresarios como sujetos de gestión les permitirá ser más competitivos en un mercado exigente que impone barreras comerciales; para ello aparece desde el pasado siglo XX la formula estimulación/recompensa desde el derecho administrativo ambiental, como uno de los incentivos a ponderarse. Con las políticas de fomento establecidas por la Administración Pública, permitirán lograr alcanzar el paradigma del desarrollo sostenible, como el megaprincipio del derecho ambiental, donde el hombre en su relación con la naturaleza y a fin de lograr la conservación de las condiciones ambientales que requiere para su hábitat sin perjuicio del desarrollo de las actividades económicas que lo impactan, necesita establecer los mecanismos, medidas y procedimientos que permitan una convivencia armónica de lo natural, de lo social y de lo económico. Se propone como objetivo demostrar la necesidad de con la implementación de la Administración Estratégica, fomentar las fórmulas de estimulación/recompensa dentro de los sujetos de gestión para alcanzar con ello el desarrollo sostenible como parte de las políticas públicas de los Estados. Son utilizados los métodos de investigación de análisis síntesis, inducción-deducción, comparación jurídica.

Palabras clave: ecoauditorias, ecoetiquetado, certificación ambiental, empresa responsable.

\section{ABSTRACT}

A look proposes the essay to the Strategic Administration, where his adequate implementation and application for the businessmen like subjects of step, will allow being more competitive in a demanding market that imposes commercial obstacles; For it appear from the past century XX the formula stimulation rewards from The Administrative Environmental right, like one of the incentives to ponder $\mathrm{m}$. With the policies of fomentation established by the Public Administration, they will enable being able to reach the paradigm of the sustainable development like the mega, beginning of The Environmental right, where the man in his relation with the nature in order to achieve the conservation of the environmental conditions that calls for for his habitat without prejudice to development the economic activities that have impact on it, and needs to establish mechanisms, measures and procedures that they enable a harmonious cohabitation of a natural, of it social and of what's economic. You set for yourself as objective, demonstrating the need of with the implementation of the Strategic Administration, fomenting the formulas of stimulation rewards within the subjects of step to attain with it the sustainable development as part of the States' public policies. The fact-finding methods are utilized the one belonging to analysis synthesis, induction deduction, juridical comparison.

Key words: ecoauditorias, ecoetiquetado, environmental certification, responsible company. 


\section{INTRODUCCIÓN}

El medio ambiente ha sido asumido a lo largo de la evolución del "pensamiento filosófico y gnoseológico" del hombre como ser social, de diferentes maneras y diversas acepciones. El hombre en su relación con la naturaleza y a fin de lograr la conservación de las condiciones ambientales que requiere para su hábitat sin perjuicio del desarrollo de las actividades económicas que lo impactan, necesita establecer los mecanismos, medidas y procedimientos que permitan una convivencia armónica de lo natural, de lo social y de lo económico. Por ello, el desarrollo tecnológico y las nuevas tecnologías no pueden ser depredadoras del medio ambiente. En esta línea, el derecho se instituye como el medio para favorecer su desenvolvimiento ambiental responsable, con el uso de los instrumentos de comando y control. Sin embargo, paralelamente al extraordinario progreso científico y tecnológico, el que ha permitido un alto nivel de vida en las sociedades desarrolladas, hoy más que nunca se advierten los innumerables riesgos originados por el propio desarrollo tecnológico y sobre los que, pese a dicho progreso, sigue presente la incertidumbre científica sobre los efectos al medio ambiente y a la salud humana.

Con ello, la implementación de los avances en las diferentes esferas de las ciencias permite encontrar soluciones a los nuevos desafíos económicos, sociales y ambientales, para favorecer el desarrollo sostenible y las sociedades verdes. De hecho, como ningún país es capaz de alcanzar el desarrollo sostenible por sí solo, la cooperación científica internacional contribuye no solo al progreso del conocimiento, sino también a la construcción de la paz. En este escenario, ayuda a los ciudadanos a comprender mejor la ciencia para que contribuyan en su desarrollo, como un hecho fundamental para construir sociedades en las que los individuos tengan los conocimientos necesarios para elegir de manera pertinente sus opciones profesionales, personales y políticas, y para que puedan participar en el apasionante mundo de la investigación, donde la cultura popular, promovida por Freire, contribuiría a alcanzar este propósito. ${ }^{1}$

Confróntese para profundizar P. Freire, Pedagogía de la autonomía. Saberes necesarios para la práctica educativa. Undécima edición en espańol (Argentina: Siglo XXI, Argentina, 2006); UNESCO, Educación para todos en 2015. ¿Alcanzaremos la meta? Panorama Regional América Latina y el Caribe (París, 2008). 
Los avances de la industria, el comercio, la ciencia y la tecnología en el siglo XXI han traído consigo enormes riesgos que amenazan no solo la salud y la estabilidad económica de los individuos o las sociedades, sino también la supervivencia de la especie humana y de la vida misma sobre el planeta tierra. Por consiguiente, lo que hace unos ańos en el pasado siglo se consideró de manera optimista como "sociedad del conocimiento", y se ha denominado por Ulrich Beck como "sociedad del riesgo", a causa de la coyuntura que vive la aldea global posmoderna y posindustrial, al enfrentar los riesgos que la modernidad misma ha engendrado, riesgos que a su vez no pueden ser calculados ni controlados por la ausencia de regulación jurídica y técnica de los sistemas políticos. ${ }^{2}$

Desde la dimensión ambiental, el nuevo paradigma es alcanzar el desarrollo sostenible, el que permitirá el tránsito de lo cuantitativo a lo cualitativo, al sentar algunas bases conceptuales de la gobernabilidad ambiental. Hay que reconocer que la raíz de la crisis ambiental ha estado en los modelos de desarrollo basados en la ganancia a cualquier costo, y es un reto alcanzar su reversión. Por ello, es una necesidad alcanzar el desarrollo sostenible en el siglo XXI toda vez que desde el informe "Nuestro futuro común" en 1984, se ha señalado como el megaprincipio del derecho ambiental; el paradigma está en cómo establecer políticas públicas para concretarlo. ${ }^{3}$

Hoy, en la conservación del deterioro ambiental influye directamente la cultura de los pueblos reflejada en las relaciones entre las personas y entre la sociedad y la naturaleza. De manera que cultura y medio ambiente están estrechamente relacionados e interdependientes. La educación ambiental como obligación pública obedece a esta misma lógica de hacer efectiva una responsable participación de la ciudadanía en las decisiones de naturaleza ambiental, pues para participar tan necesario es estar informado como estar formado. La tendencia en el mundo empresarial se direcciona hacia modelos de negocios amigables con el ambiente en el siglo XXI. Estos conciben que la viabilidad económica de las formas de gestión en los desafíos en el mundo actual no solo depende de su gestión económica, sino también de su gestión responsable en aspectos ambientales y sociales, dimensionando las necesidades presentes sin comprometer las ventajas y oportunidades potenciales del futuro que les permitan ser más competitivas ante mercados más exigentes.

Son hechos que demuestran que la incidencia de la Administración Estratégica en la Responsabilidad Social Empresarial (RSE) es un elemento a ponderarse para la conformación de

2 Véase en este sentido, U. Beck, Politicas ecológicas en la edad del riesgo. Antidotos. Responsabilidad organizada (Barcelona: El Roure, 1998); U. Beck, La sociedad del riesgo. Hacia una nueva modernidad (Barcelona: Paidós Ibérica, 1998); J. Esteve Pardo, Técnica, riesgo y derecho. Tratamiento del riesgo tecnológico en el derecho ambiental (Barcelona: Ariel, 1999); H. Granja Arce, "Nuevos riesgos ambientales y derecho administrativo" (tesis de maestría, Colegio Mayor Nuestra Señora del Rosario, 2010).

3 G. Harlem Burtland recibió de las Naciones Unidas el encargo de presentar el informe Nuestro futuro común (ONU: Estados Unidos de América, 1984), 1-33. 
la empresa responsable con el ambiente desde la dimensión ambiental con la implementación de tecnologías limpias, el uso adecuado de los sistemas de gestión ambiental, la auditoría ambiental, la etiqueta ambiental para lograr el desarrollo sostenible dentro de los instrumentos de mercado y comercio como parte de las fórmulas estimulación/recompensa, que son elementos incidentes en la calidad de vida y el bienestar a los ciudadanos a partir de la tutela adecuada de la Administración Pública, y que hoy son un reto para alcanzarlo como parte de las políticas públicas, donde aparece en este escenario su control por parte de los sujetos privados. El ensayo propone como objetivo demostrar la necesidad de con la implementación de la Administración Estratégica fomentar la fórmula de estimulación/recompensa dentro de los sujetos de gestión para alcanzar con ello el desarrollo sostenible como parte de las políticas públicas de los Estados. Para ello, son utilizados los métodos de investigación de análisis, síntesis, inducción-deducción, comparación jurídica.

\section{EL DERECHO ADMINISTRATIVO AMBIENTAL}

La Conferencia sobre el Medio Humano, convocada por la Asamblea General de Naciones Unidas y reconocida como la Declaración de Estocolmo, es el hecho jurídico que marca un hito en el desarrollo del derecho ambiental moderno. Fue esta cita el inicio fundacional del derecho ambiental, el primer documento en un foro internacional, señalado como el maridazgo que existe entre el derecho ambiental y el derecho internacional; de aquí su nexo con el derecho internacional. Por el grado de consenso generado entre los Estados, y la profundidad de sus conceptos, esta Declaración se reconoce como la "Carta Magna” del derecho internacional ambiental, ${ }^{4}$ aunque, como señalara Jordano Fraga, “... resulta artificioso y atrevido fijar una fecha concreta o una norma a partir de la cual se pueda situar el nacimiento del derecho ambiental moderno...". 5

Por ello, tanto el Pacto Internacional de Derechos Civiles y Políticos (1966) como el Pacto Internacional de Derechos económicos, Sociales y Culturales (1966) proclaman en su artículo 1 el derecho de los pueblos a la libre determinación, y en su virtud "establecen libremente

4 En este sentido, véase PNUMA, Declaración del Día Mundial del Medio Ambiente, la preservación del medio ambiente, para concientizar a los pueblos y a los estadistas (Brasil, 1992); J. Juste Ruiz, Derecho internacional del medio ambiente (Madrid: McGraw-Hill, Madrid, 1999); J. Juste Ruiz, La evolución del derecho internacional del medio ambiente (España: Universidad de Valencia, 2007).

5 Resulta interesante conocer las posturas detractoras a las que se refiere J. Jordano Fraga, La protección del derecho a un medio ambiente adecuado (Barcelona: J. M. Bosch, 1995), 50 y ss. al señalar que, en los Estados Unidos de América, la Environmental Policy Act de 1969 desmiente que el origen del derecho ambiental moderno se sitúe en la Conferencia de Estocolmo de 1972. Así, refiriéndose a Rodgers Environmental Law, St. Paul, Minnesota, West Publishing Company, 1977, p. 697, seńala que este autor sostiene que la Environmental Policy Act es una norma fundamental y pionera que introduce por primera vez en los tribunales federales de USA las cuestiones ambientales comprensivamente, expande el alcance del control jurisdiccional sobre la actuación administrativa, introduce nuevas normas y valores en el proceso de decisiones administrativas y refuerza el poder del Congreso en la supervisión de las actuaciones de la Administración con efectos ambientales adversos; cuestión distinta es que no tenga el alcance deseado. 
su condición política y proveen asimismo a su desarrollo económico social y cultural”. Para el desarrollo de sus fines (art. 1.2), "todos los pueblos pueden disponer libremente de sus riquezas y recursos naturales, sin perjuicio de las obligaciones que derivan de la cooperación económica internacional ...". ${ }^{6}$

Estas obligaciones para los Estados se recogen, de forma genérica, en el cuarto principio de la Declaración de Río sobre el Medio Ambiente y el Desarrollo, que proclama que "la protección del medio ambiente debe formar parte integrante del proceso de desarrollo y no puede considerarse aisladamente". Con la Declaración de Río, el concepto de sostenibilidad aparece como un límite a la libre disposición de estos recursos naturales. Después de Río de Janeiro en 1992, la Cumbre de Johannesburgo de 2002, la Cumbre de Río+20 de 2012 y la Cumbre del Cambio climático en 2015, se ha reafirmado la voluntad política de continuar adoptando medidas para mitigar los problemas ambientales que hoy se plantean a escala global por los Estados. ${ }^{7}$

En América Latina, la novedad que distingue a esta región es que en el siglo XXI aparece el reconocimiento del pluralismo jurídico De Jure, donde se le han concedidos derechos a la naturaleza como sujeto, hecho jurídico registrado en los ordenamientos jurídicos de Bolivia y Ecuador a través de la pachamama y el sumak kwasay. Ello es una novedad revolucionaria dentro del derecho constitucional ambiental con el buen vivir, ${ }^{8}$ constructo en desarrollo en la nación ecuatoriana como nuevo paradigma. Retomado de los saberes ancestrales de los pueblos y nacionalidades indígenas, que implica vivir en armonía con uno mismo, con la naturaleza y los demás, en la construcción de Estados democráticos, incluyentes, plurinacionales e interculturales. ${ }^{\text {? }}$

Sin embargo, hay que significar que la respuesta del derecho frente a estas actuaciones humanas no ha sido siempre la misma, como tampoco han trascendido de igual modo para el ambiente en general las actividades del hombre. Hasta que la presión sobre el medio

6 Vease para ello, A. Pérez Luño, La tercera generación de derechos humanos (Pamplona: Thomson Aranzadi, 2006); I. Soler Tormo, "La configuración constitucional del medio ambiente como derecho" (tesis doctoral, Universidad de Valencia, 2016).

7 Consultar textos jurídicos, en este sentido Declaración de Rio, sobre el medio ambiente y el desarrollo, ONU, 1992; Declaración de Johannesburgo sobre el desarrollo sostenible, ONU, 2002; Declaración Rio+20, Brasil, 2012; Convención sobre el Cambio Climático, París, ONU, 2015, y la Agenda 2030 para el desarrollo sostenible, ONU, 2015

8 A. Rodríguez Salazar, "Teoría y práctica del buen vivir: orígenes, debates conceptuales y conflictos sociales. El caso de Ecuador" (tesis doctoral, Universidad del País Vasco, 2016).

9 Para profundizar, consúltese en este sentido D. Quirola Suárez, Sumak Kaway. Hacia un nuevo pacto social en armonía con la naturaleza (Quito: Abya-Yala, 2009), 103; R. Llasag Fernández, Los derechos de la naturaleza y la naturaleza de sus derechos (Quito: Ministerio de Justicia y Derechos Humanos, 2011), 82; C. Villavella Armengol, El derecho constitucional del siglo XXI en Latinoamérica: un cambio de paradigma. Estudios sobre el nuevo constitucionalismo latinoamericano (Valencia: Tirant lo Blanch, 2012), 51-76; F. Vega, "El buen vivir sumak kawsay en la Constitución y en el PNBV 2013-2017 del Ecuador", OBETS, n. 1 (2014); A. Antúnez Sánchez, y E. Díaz Ocampo, "El pluralismo jurídico en América Latina”, Dos Tribunais, n. ${ }^{\circ} 990$ (2018). 
no alcanzó una repercusión global, y esta adquirió magnitudes fácilmente perceptibles, la respuesta jurídica no pasó de las regulaciones sectoriales de determinadas actividades con trascendencia sobre aquel. Los bienes ambientales protegidos se irán ampliando por diferentes motivaciones de manera particularizada, sin que esta protección se extienda de forma generalizada a todo el entorno. El derecho en esta fase inicial, solo será un remedio para prohibir determinadas conductas degradantes, pero no para producir cambios sustanciales en los ecosistemas. ${ }^{10}$

\section{Jordano Fraga considera que}

... desde la perspectiva del derecho interno, lo que resultó más significativo para el derecho ambiental en ese momento no fue tanto las técnicas jurídicas que se recogieron en las diversas normas aprobadas, sino en el surgimiento del medio ambiente como objeto de derecho. De este modo, lo novedoso no radicaba en los instrumentos jurídicos que el nuevo derecho ponía en carga en el ordenamiento jurídico, los cuales respondían al resultado de experiencias de la normativa sectorial precedente sobre recursos naturales, la lucha contra la contaminación y la conservación de la naturaleza, sino en la aparición de un derecho ambiental que llegaba para quedarse con sustantividad propia... ${ }^{11}$

De esta preocupación para su remediación, participan no solo los científicos y especialistas sino toda la sociedad, tanto por la mayor percepción de su deterioro, como por una serie de factores en modo alguno desdeñables. Actualmente en esta relación puede hablarse de "resiliencia”, entendida como la capacidad humana de sobreponerse al dolor emocional y a situaciones adversas. Aunque el concepto proviene de la psicología, se aplica también al ámbito de la ecología y de la economía. Nos dice que la especie humana se ha visto obligada a adaptarse, con mayor o menor dificultad, al ambiente que le ha tocado en suerte, pero también a las circunstancias ambientales por él creadas. Es imposible imaginar la existencia desde un absoluto aislamiento aséptico (que en este caso también constituiría un entorno) como medio en el que se desarrolla la vida, cuando la persona se define por su capacidad de comunicarse, de establecer relaciones. Los humos de las industrias y los vehículos, los ruidos, las basuras, pero también los espacios abiertos, bosques, ríos, construcciones y demás elementos de la naturaleza y obras humanas forman parte de un hábitat que ha sido destruido, deteriorado, conservado y cuidado por el hombre. Medio que legaron las generaciones pasadas y por el que pedirán responsabilidades las futuras.

10 Véase para ello, R. Brañes, Manual de derecho ambiental mexicano (México: Fondo de Cultura Económica, 1994), 18. En el mismo sentido, D. Loperena Rota, El derecho al medio ambiente adecuado (Madrid: Civitas, 1996), 21.

11 Confróntese J. Jordano Fraga, La protección del derecho a un medio ambiente adecuado (Barcelona: J. M. Bosch, 1995), 50 y ss.; A. Bengoechea Morancho, Dimensión medioambiental de la responsabilidad social corporativa (La Coruna: Netbiblo, 2010), 10. 
Fernández de Gatta Sánchez valora que

... en la actualidad, la protección del medio ambiente de los variados y agresivos agentes contaminantes requiere una acción pública eficaz y diversificada, debido al origen y contenido de los peligros y riesgos ambientales. Se requiere, pues, una directa intervención pública ordenando, inspeccionando y sancionando las conductas humanas, es decir, utilizando el poder de autoridad, ya que el mercado no protege el medio ambiente, sino que, más bien, lo deteriora... ${ }^{12}$

En consecuencia, el impacto sobre el medio ambiente o el bienestar económico de un desastre no depende únicamente de las características físicas del evento o de la capacidad destructiva de su impacto directo, sino también, y de forma destacada, de su capacidad de superarlo y de autorregenerarse. Tanto en el medio natural, como en las estructuras sociales, se evidencia, como se verá, que una mayor diversidad determina una menor vulnerabilidad y una mayor capacidad de regeneración, en definitiva, de una mayor "resiliencia". Esta depende en gran medida de la biodiversidad, y esta biodiversidad depende tanto de la abundancia relativa de seres vivos en un ecosistema, como de la disimilitud conjunta de especies, que facilitan la adaptación general a los impactos adversos. ${ }^{13}$

En este sentido, autores como Parejo Alfonso, Sanz Rubiales, Gago y Lavandeira lo han significado en sus estudios ${ }^{14}$ desde la ciencia del derecho administrativo ambiental, de cómo las normas jurídicas incidirán en acciones positivas ante el cambio climático, con la implementación de los impuestos ambientales, de la fiscalidad ambiental, de los instrumentos de carácter cooperador, y las acciones para su mitigación por parte de Estados contaminadores a escala global, donde desde la Unión Europea ha sido un paso de avance para dar respuesta con políticas públicas trazadas en los ordenamientos jurídicos adoptados por los Estados que componen este continente. Al mismo tiempo, se aprecia como el hecho ambiental y su repercusión sobre la salud, la calidad de vida y hasta la vida de las personas, se impone como una realidad a la que es imposible permanecer ajeno. Fue la preocupación por la evidencia la que motivó el tratamiento de estos hechos como derechos, planteando la posibilidad de denuncia de los mismos y la consiguiente reacción, primero parcial y después global del legislador. Con ella vino el reconocimiento tanto del derecho a disfrutar del ambiente como la inaplazable

12 D. Fernández de Gatta Sánchez, "La responsabilidad social corporativa en materia ambiental. Estado de la cuestión”, Boletín económico ICE, $\mathrm{n} .^{\circ} 2824$ (2004).

13 S. Hallegatte, "Economic Resilience, Definition and Measurement", Policy Research Working Paper, n. 6852 (2014).

14 Para profundizar, consúltese M. T. Carballeira Rivera, "El cambio climático. Análisis científico y jurídico del problema de la emisión de gases de efecto invernadero", Revista de Derecho Urbanistico y Medio Ambiente, n. ${ }^{\circ} 156$ (1997); L. Parejo Alfonso, El derecho ante la innovación y los riesgos derivados del cambio climático (España: Tirant lo Blanch, 2015); I. Sanz Rubiales, Cambio climático y Unión Europea: presente y futuro del mercado europeo de emisiones (España: Tirant Lo Blanch, 2014); A. Embid Irujo, Agua, energía, cambio climático y otros estudios de derecho ambiental. Primera edición (España: Aranzadi, 2015). 
necesidad de su protección. No obstante, hay que significar que la relación del hombre con su entorno no ha sido únicamente de destrucción. Se comunica, crea, produce obras de arte, literatura, música, fabrica utensilios, construye caminos, herramientas, casas, ciudades, medios de transporte, etc., denominándolo como medio ambiente construido, tributando a lograr el desarrollo sostenible con este entorno de manera armónica. ${ }^{15}$

Por ello, se sostiene que a partir de finales del siglo XX y principios del XXI, la sociedad ha dado un giro desmesurado y de difícil control para el Estado. Es así como la gran magnitud del uso de la Internet y la globalización han llevado a eliminar muchas fronteras que antes existían, escapándose al control tradicional del Estado. Esta apertura de fronteras, de cultura y de libre información comprende elementos que plantean nuevos cuestionamientos para el derecho como ciencia social, demandando una nueva regulación, pues en no pocas ocasiones se presentan conflictos éticos que colisionan con la garantía y el respeto de los derechos humanos fundamentales, sumándole la especialidad y tecnicismo peculiar de los nuevos poderes que se componen en la sociedad actual; ante ello la Administración Pública debe revisar sus actuaciones para lograr ser más eficaz y eficiente en el cumplimiento de sus funciones y no quedar inmersa en un derecho anacrónico. Ya reseñábamos que una de estas ha sido la ejecución a través de la inspección y la auditoría por sujetos privados, la que está necesitada de mayor información y conocimientos, donde la hipercultura jurídica podrá coadyuvar en este sentido.

$\mathrm{Al}$ ser un suceso en el mercado mundial, las fuerzas de la economía de mercado han abierto circuitos y formado organizaciones de muy difícil control por el Estado, que imponen su dominio en ámbitos como las telecomunicaciones, la biotecnología, la energía, la industria y los medios de comunicación; estos poderes se constituyen al margen de la regulación e intervención de los poderes públicos estatales por la sencilla razón de que les resultan inaccesibles y, por ello, incontrolables. ${ }^{16}$ Ello es un reto importante para el derecho, el que ha de renovar muchos de sus objetivos e instrumentos al verse radicalmente alterada la posición de los poderes y fuerzas que ha de dominar y racionalizar. El empleo de las nuevas técnicas de regulación pública está fuertemente enlazado con los extraordinarios cambios que han sufrido algunos sectores que son objeto de intervención por parte del poder público, primordialmente aquellos que se han visto considerablemente influenciados por los avances científicos de las últimas décadas, dando un giro a la comprensión del mundo contemporáneo, la sociedad, la economía, la política, abriendo paso así a una nueva concepción de la sociedad marcada por la revolución tecnológica y la cultura del riesgo. ${ }^{17}$

15 E. García de Enterría y L. Parejo Alfonso, Lecciones de derecho urbanistico (España: Editorial Civitas, 1981), 51 y ss; J. Bermejo Vera, Derecho administrativo. Parte especial (Madrid: Civitas, 1994), 456.

16 J. Esteve Pardo, Autorregulación, génesis y efectos (España: Editorial Aranzadi, 2002), 21-22.

17 Cfr. J. Esteve Pardo, Técnica, riesgo y derecho: tratamiento del riesgo tecnológico en el derecho ambiental (Barcelona: Ariel, 1999). 
Su objetivo no sería la imposición autoritaria de mandatos o prohibiciones, sino la de incentivar y encauzar la propia moderación y contención de las fuerzas y agentes sociales. Dentro de este contexto, se aprecia cómo el régimen de protección del medio ambiente está haciendo uso de nuevas técnicas autorregulatorias para lograr su cometido, dentro de las cuales encontramos las ecoauditorías. En consecuencia, el futuro inmediato del derecho ambiental parece orientado hacia fórmulas de autorregulación y una concepción reflexiva del derecho, si pretende operar eficazmente sobre el núcleo de los sistemas generadores de riesgos y no quedarse en un despliegue de intervenciones de la vieja policía administrativa. Los problemas relacionados con el medio ambiente y su protección para las generaciones presentes y futuras de los seres humanos están en el centro de atención de las instituciones científicas, los políticos, los grupos ecologistas y las personas comunes en todos los países, por la estrecha interdependencia que tienen respecto a la calidad de vida de los pueblos y hasta para la supervivencia de la sociedad.

En este iter, se concibe que la autorregulación regulada constituya una importante y decisiva línea de progreso del derecho en el futuro más inmediato en el siglo XXI. Este es un fenómeno privado, por lo que sus actores son los particulares, sean personas físicas o jurídicas de derecho privado de un mismo sector de mercado profesional, industrial, económico, nuclear, ético, etc., particulares que están en la misma órbita de actuación, creando así su sistema de referencia con ciertas condiciones de validez, que van a regular y orientar sus actuaciones dentro del mismo espacio que comparten, generando los instrumentos normativos o referenciales vinculantes para sus miembros. En el derecho administrativo ambiental se tiene en cuenta la autorregulación privada cuando los poderes públicos, conscientes de sus limitaciones, recurren a ella para la satisfacción de los intereses generales. Las limitaciones de conocimiento, como de su propia capacidad de gestión y control, propician la toma en consideración de las decisiones, pautas y criterios asentados en los distintos substratos profesionales. Se da entrada en la satisfacción de los intereses públicos a la participación de los agentes sociales y con ello se reconoce la incapacidad pública en determinados ámbitos, así como las ventajas de una articulada y controlada colaboración con el sector privado. ${ }^{18}$

En este mismo sentido, en las últimas décadas desde el pasado siglo XX algunos instrumentos normativos producto de la autorregulación privada ampliaron su cobertura hacia una esfera que ya no se limita a los sujetos partícipes de dichos procesos, sino que además entran a formar parte del ordenamiento jurídico, adquiriendo así la condición de normas de derecho objetivo, de obligada observancia y que se toman como referencia también por los poderes públicos, administraciones y tribunales, destacando las normas técnicas, las ecoauditorías, los

18 Profundícese en este sentido, M. Rodríguez Font, Régimen de comunicación e intervención ambiental. Entre la simplificación administrativa y la autorregulación (España: Atelier, 2003), 132; M. Darnaculleta Gardella, Autorregulación y derecho público: la autorregulación regulada (Barcelona: Marcial Pons, 2005). 
protocolos de actuación y los códigos de conducta. ${ }^{19} \mathrm{El}$ resultado normativo de los procesos de la autorregulación privada de los distintos sectores y sistemas de la sociedad representa hoy una nueva fuente para el derecho administrativo ambiental, una vez que la Administración les otorga a estos efectos públicos. Es por ello que la autorregulación es el fenómeno más innovador que se registra en torno al ordenamiento en la última década y del que ya no puede prescindirse en la teoría de fuentes del derecho administrativo. ${ }^{20}$

Se ha concebido que la integración de la dimensión ambiental en la política de cualquier organización, sea empresarial o no, es más que una estrategia comercial y publicitaria, se convierte en un elemento esencial, determinante en el conjunto de su proceso de toma de decisiones y en su propia gestión interna de los sujetos de gestión con una clara visión de su ámbito de actuación. Los requerimientos ambientales deben ser percibidos, planificados y asumidos como elementos potenciales de prestigio y competitividad dentro de la organización. He aquí donde deberá jugar un rol la Administración Estratégica en la toma de decisiones por los empresarios desde la ciencia de la administración. Lo que incidirá en el logro del concepto innovador como megaprincipio del derecho ambiental, al concebirse que el desarrollo sostenible es "aquel que satisface las necesidades esenciales de la generación presente sin comprometer la capacidad de satisfacer las necesidades esenciales de las generaciones futuras...". ${ }^{21}$

Elementos que inciden para que, en el 2001, surgiera el término en el Libro Verde sobre responsabilidad social de las empresas publicado por la Comisión de las Naciones Europeas. Es aquí donde el sujeto de gestión empresarial social y ambientalmente responsable se preocupa del bienestar de quienes trabajan en ella, desde el punto de vista de salud, seguridad e higiene, educación, remuneración justa, procesos de selección adecuado, respeto al ambiente, reducción de impactos negativos, ahorro de energía, uso de tecnologías limpias. Se preocupa en general por el bien común. ${ }^{22}$

Por último, ante el reconocimiento de que el modelo económico y social de los países industrializados ha constituido desde antaño hasta nuestros días, el principal elemento en la degradación del medio ambiente incidente en la salud y calidad de vida de los seres humanos del globo terráqueo. Puesto que la articulación de las políticas vinculadas a la protección del medio ambiente debe realizarse a través de cuerpos jurídicos adecuados con una visión trans-

19 Consúltese, para profundizar, J. Esteve Pardo, Lecciones de derecho administrativo. Cuarta edición (Madrid: Marcial Pons, 2014), 84; L. Arroyo Jiménez, Introducción a la autorregulación, autorregulación y sanciones. Primera edición (España: Lex Nova, 2008), 20-23.

20 Consúltese en este sentido, J. Esteve Pardo, Lecciones de derecho administrativo (Madrid: Marcial Pons, 2014), 59-83; A. Pérez Luño, El desbordamiento de las fuentes del derecho (Sevilla: Real Academia Sevillana de Legislación y Jurisprudencia, 1993), 52.

21 Comisión Mundial del Medio Ambiente y del Desarrollo, Nuestro futuro común (España: Editorial Alianza, 1988 ), 29.

22 Comisión de las Comunidades Europeas, Libro Verde. Fomentar un marco europeo para la responsabilidad social de las empresas (Bruselas: Comisión de las Comunidades Europeas, 2003). 
versal, como subramas del derecho ambiental, en el derecho urbanístico, el derecho minero, el derecho forestal, el derecho nuclear, el derecho de aguas. Sin desdeñar otra rama de las ciencias que aborda el tema ambiental, como son las ciencias ambientales. ${ }^{23}$

Sanz Larruga señala en este sentido, en relación con las formas de gestión, que

la empresa estaba acostumbrada al conflicto intraempresario, es decir, al conflicto entre patrón, empleador y trabajador, conflicto de derecho del trabajo y al conflicto inter-empresario de derecho comercial, conflicto con el cliente y con el proveedor. De pronto se ve inmersa en otro tipo de conflicto, de base social, porque el Derecho Ambiental es un derecho de grupo, de clase, de categoría, ligado a una pluralidad de sujetos integrantes de un grupo, vinculados en virtud de una pretensión de goce de una misma prerrogativa, al ser un derecho de goce, disfrute y afectación solidaria. ${ }^{24}$

En este escenario, el fomento, institución jurídica del derecho administrativo ambiental, se perfila como la medida idónea para implicar a la ciudadanía en la protección ambiental y maximizar resultados; ${ }^{25}$ junto a estas estrategias, se unen las técnicas extraídas del mundo empresarial y adaptadas al ámbito público, como son la normalización y certificación aplicadas a través de una Administración Estratégica por parte de los sujetos de gestión que las implementen de manera adecuada con eficacia y eficiencia. Para ello, mediante la cooperación y fórmulas consensuadas pueden en principio superarse ciertos rigores o asperezas de la normativa y vencer las resistencias del sujeto destinatario, ganando en lo posible su colaboración. Nogueira López conecta la adopción de un sistema de gestión ambiental con un nivel de autoexigencia ambiental superior al establecido legamente. Se trata de una corresponsabilidad ligada a los principios de prevención y del desarrollo sostenible. ${ }^{26}$

23 Las ciencias ambientales constituyen la disciplina científica que se ocupa de buscar y conocer las relaciones que mantiene el ser humano consigo mismo y con la naturaleza. Incluye áreas de estudios multidisiciplinarios abarcando diversos elementos de la naturaleza, incluye el estudio de los problemas ambientales y propone modelos para alcanzar el desarrollo sostenible; Agencia Nacional de la Calidad y Evaluación, Libro Blanco. Ciencias ambientales (España: Agencia Nacional de la Calidad y Evaluación, 2004).

24 Consúltese para profundizar, F. Sanz Larruga, "Sostenibilidad ambiental y derecho administrativo: ‘nuevo remedio ante la crisis económica o una exigencia constitucional? A propósito de la nueva Ley de Economía Sostenible”, VI Congreso de la Asociación de profesores de Derecho Administrativo, Palma de Mallorca, 2011; A. Pérez Luño, Derechos humanos, Estado de derecho y Constitución (Madrid: Tecnos, 2010), 463; F. Simón Yarza, Medio ambiente y derechos fundamentales (Madrid: Centro de Estudios Políticos y Constitucionales, 2012), 13-16.

25 Profundícese en este sentido, S. Rodríguez-Campos González, "El fomento de la ecoauditoría como estrategia interventora", Revista Española de Derecho Administrativo, n. ${ }^{\circ} 119$ (2003): 382. La doctrina ha destacado la idoneidad de la técnica elegida y del fin que con ella se consigue: la protección del medio ambiente entendida más que como un interés general cuya tutela es monopolio del Estado, como un objetivo último en cuya plasmación deben colaborar los agentes públicos y sujetos privados; E. J. Ruiz Vieytez, El derecho al ambiente como derecho de participación (Zarautz: Ararteko, 1990), 310; D. Fernández de Gatta Sánchez, Sistema jurídico-administrativo de protección del medio ambiente. Tercera edición (España: Ratio Legis, 2014), 29.

26 Consúltese en este sentido, para profundizar, A. Nogueira López, "Ecoauditorías, intervención pública ambiental y autocontrol empresarial", Revista Aragonesa de Administración Pública, n. ${ }^{\circ} 12$ (2000); A. Nogueira López, "Hacia un EMAS de alcance internacional en competencia con la ISO 14001: notas a la revisión del Reglamento EMAS", Revista Actualidad Jurídica Ambiental (2010). 
Gray, Bebbington y Walters señalan en este sentido que "la necesidad de una respuesta sustancial a la crisis ambiental mundial de parte de las organizaciones en general y de los negocios en particular nunca ha sido más evidente o más urgente". ${ }^{27}$

Estos autores consultados aseveran que

existen dos razones principales para ello. Primero, está claro que, en el clima político actual, para que se dé cualquier progreso en la reducción de la tasa de destrucción ecológica, los negocios tendrán que jugar un mejor papel $\mathrm{y}$, realmente, mostrar que lo están haciendo. Segundo, la amplia experiencia muestra que: a) la gente de negocios necesita alguna orientación, algunos indicadores de desempeño, sobre sus logros en la actividad ambiental se necesitaría algo así como un sistema de información paralelo o incorporado al actual sistema de información contable; b) la actual práctica contable y las estructuras conceptuales contable y financiera presentes impiden tanto las iniciativas ambientales como la orientación positiva de las actividades ambientalmente malignas.

En esta cuerda, Leff considera que

La historia ha dibujado a un hombre que enfrentó a la naturaleza, en la actualidad emerge la necesidad de un hombre ecológico que comparta los poderes tecnológicos que ha logrado con una racionalidad diferente, con una inteligencia inclinada hacia la preservación y cuidado de sí mismo desde el medio natural que es él mismo en otra dimensión. Nos encontramos en un momento en que el pensamiento se identifica con un estado de “...inflexión de la historia que induce una reflexión sobre el mundo actual de donde emergen las luces y las sombras de un nuevo saber... ${ }^{28}$

Por ello, hoy con el interés de continuar generando riquezas y cuidar el medio ambiente, se ha generado el concepto de ecoinnovación. Es todo tipo de innovación que contribuye al desarrollo sostenible, reduciendo el impacto ambiental y optimizando el uso de los recursos. En términos de innovación, ecoinnovación se refiere a la creación de productos y procesos que reduzcan el deterioro del medio ambiente. Desde el punto de vista económico, la ecoinnovación busca que las empresas hagan un uso adecuado de los recursos naturales para mejorar el bienestar humano. Se considera, entonces, que esto se concreta con la aplicación en la investigación de las condiciones de partida de la Economía Basada en el Conocimiento (EBC), así como las medidas implementadas que dieron origen a la Empresa de Alta Tecnología (EAT),

27 Para profundizar consúltese R. Gray, J. Bebbington y D. Walters, Contabilidad y auditoría ambiental (Bogotá: Ecoe Ediciones, 1999), 9; F. Popoff, "Contabilidad de costos ambientales, un nuevo paradigma para la industria", Revista Ambiente y Desarrollo (2013); P. Guzmán Aguilera, Introducción al análisis económico del derecho ambiental. Primera edición (Bogotá: Universidad Externado de Colombia, 2006); G. Real Ferrer, "La construcción del derecho ambiental", Revista Aranzadi de Derecho Ambiental, n. ${ }^{\circ} 1$ (2002).

28 Enrique Leff, Los derechos del ser colectivo y la reapropiación social de la naturaleza: a guisa de prólogo a Justicia ambiental: construcción y defensa de los nuevos derechos ambientales, culturales y colectivos en América Latina, de Enrique Leff (México D.F.: PNUMA/CEIICH-Unam, 2001). 
y con ello desde la arista de las ciencias jurídicas se sugieren algunas recomendaciones esenciales desde una perspectiva macroeconómica e institucional, enfatizando en la importancia de la secuencia y consistencia de este programa. Se valora que la EBC es un elemento determinante para la Administración Pública al ser aplicada a las empresas y al conjunto de los sujetos de gestión del sector estatal para desarrollar la economía de un país, toda vez que incrementa el producto interno bruto; de ella depende cada vez más su efectividad para generar y utilizar conocimientos por su vínculo con la Empresa de Alta Tecnología, la que pondera la protección del medio ambiente.

Ello permite justipreciar que las sociedades que se basan en el desarrollo del conocimiento lo hacen por su dependencia de un conjunto de artefactos físicos e instituciones culturales cuya producción y articulación requieren de conocimientos. El rasgo distintivo de las sociedades modernas basadas en el conocimiento se distingue por el alcance y el ritmo del crecimiento económico, así como la alteración en la acumulación y transmisión de los conocimientos, donde gran parte de los cuales son nuevos o se desenvuelven en contextos distantes del que los vio nacer.

En este orden, Kuznets refiere que

el carácter central de la base de conocimientos en las economías avanzadas, son aquellas economías que han experimentado la mayor discontinuidad en la creación y distribución de conocimientos, la que tiene múltiples implicaciones para el desarrollo económico, tecnológico y social. Por ejemplo, la tasa agregada de crecimiento de las principales economías depende cada vez más de la creación de nuevas industrias, cuyas tasas de crecimiento superan a las de los sectores establecidos y, por lo tanto, aumentan la tasa media de crecimiento del conjunto de la economía. ${ }^{29}$

Se precia, así, que la expresión —economía basada en los conocimientos— capta una diferencia cualitativa en la organización y conducta de la vida económica moderna. Los autores constatados que utilizan la expresión EBC sostienen que los determinantes del éxito de las empresas y del conjunto de la economía de un país determinado dependen cada vez más de su efectividad para generar y utilizar conocimientos, términos con los que se coincide. Desde la ciencia de la administración será necesario utilizar las técnicas del marketing empresarial y aplicar los principios de eficiencia, eficacia y legalidad desde las ciencias jurídicas y en particular desde el derecho administrativo. Empero, a pesar de que el conocimiento científico y tecnológico tiene una importancia clave, el conocimiento acerca de cómo organizar y gestionar las actividades económicas, especialmente aquellas que comprenden la aplicación de nuevas perspectivas científicas y tecnológicas, también es un determinante crucial del rendimiento

29 S. Kuznets, Modern Economic Growth: Rate, Structure, and Spread (El crecimiento económico moderno: tasas, estructura y margen) (New Haven y Londres: Yale University Press, 1996). 
económico. Demuestran que este progreso organizacional y de gestión está cobrando importancia a medida que aumenta el contenido científico y tecnológico de la actividad económica, que hoy viene señalando la implementación de la RSE con la construcción de la empresa responsable para este fin, al ponderar la arista económica, social y la ambiental. Toda vez que su naturaleza jurídica está centrada en la introducción, aplicación y comercialización de nuevas tecnologías basadas en la EBC.

Lo antes valorado nos lleva a analizar el documento aprobado en la Unión Europea en Lisboa 2000, donde se acordará un nuevo objetivo estratégico de la Unión a fin de reforzar el empleo, la reforma económica y la cohesión social como parte de una economía basada en el conocimiento. Su objetivo estratégico fue hacer la EBC más competitiva y dinámica, capaz de crecer económicamente de manera sostenible, con más y mejores empleos y con mayor cohesión social a escala global. ${ }^{30}$ En este documento fueron ponderados aspectos como preparar el paso a una economía y una sociedad basadas en el conocimiento mediante la mejora de las políticas relativas a la sociedad de la información y de la investigación más desarrollo (I+D). Ello permite el paso a una economía digital basada en el conocimiento. El fruto de nuevos bienes y servicios será un poderoso motor para el crecimiento, para la competitividad y el empleo. Además, será capaz de mejorar la calidad de vida de los ciudadanos y del medio ambiente. ${ }^{31}$

Ahora, ¿qué es en sí la EAT? Es la empresa como sujeto de gestión que invierte una parte importante de sus recursos en investigar nuevos procesos y productos, que se sustituyen por otros mejores, que protegen sus conocimientos con patentes desde el derecho de propiedad industrial, que se involucran en frecuentes transacciones sobre activos intangibles, y emplean una fuerza de trabajo de alta calificación. Son las llamadas EAT, como parte de una etapa nueva del desarrollo que se conoce como la economía del conocimiento (EBC). Se caracteriza por transformar la ciencia en productos y en servicios comercializables, en un proceso complejo que requiere nuevas investigaciones. Su génesis aparece con la transformación de estas premisas tecnológicas en la industria, que se inició en algunos lugares de los Estados Unidos a finales de los 70' y principios de los 80', del pasado siglo, con la aparición de múltiples pequeñas empresas biotecnológicas que aprovecharon el momento favorable de la economía de ese país para movilizar capital de riesgo de inversionistas privados, o de la bolsa de valores, consustancial con el desarrollo industrial de esta nación y su problemática ambiental al regularse en cuerpos jurídicos que ponderaron la protección ambiental en normas jurídicas federales y estaduales. ${ }^{32}$

30 El Plan de Acción de Europa tiene como objetivo fundamental lograr la conectividad de Europa en el período de tiempo más breve posible; se centra en tres áreas claves: Internet barato, rápido y seguro, inversión en capital humano, estimulación del uso de Internet.

31 M. Callejón, “I+D, innovación y política pública: hacia una nueva política económica de innovación”, Revista sobre la Sociedad del Conocimiento, n. ${ }^{\circ} 4$ (2007).

32 M. Ludevid, La gestión ambiental de la empresa (Barcelona: Ariel, 2000). 
En Europa, no comienza hasta finales de los $80^{\prime}$, y allí el acceso a capital de riesgo no ocurre hasta mediados de los 90', del siglo XX. En el resto del mundo, el fenómeno es un tema incipiente, debido a sus altos costes y la necesaria calificación del capital humano que permita concebir este tipo de empresa. Nos da como lectura que el progreso y evolución de la EAT se ha ido desarrollando en el campo de la biotecnología, esencialmente en el uso de bacterias, de las levaduras, de las células animales y vegetales, cuyo metabolismo y capacidad de biosíntesis se orientan hacia la fabricación de sustancias específicas. ${ }^{33} \mathrm{Su}$ asidero jurídico dentro de los ordenamientos jurídicos se constata que ha tenido como soporte el derecho constitucional a través de la carta magna, y se ha desarrollado en el derecho sustantivo a partir de cuerpos jurídicos vinculados al derecho administrativo, al derecho laboral, al derecho ambiental, al derecho mercantil, al derecho informático, entre otras ramas de las ciencias jurídicas vinculadas con el derecho de la empresa. Por su transdisciplinariedad, se valora su vínculo como sujeto de gestión con las ciencias empresariales, con la ingeniería industrial, con las ciencias informáticas, con las ciencias contables y económicas, con las ciencias ambientales, con las ciencias de la administración, entre otras. Por esta razón, se justiprecia que podrá aplicarse para el fomento de la EAT desde el derecho administrativo ambiental en las naciones que implementen la fórmula Investigación +Desarrollo+Innovación+Etiqueta-CertificaciónAmbiental $=$ Empresa Responsable con el Ambiente, como una de las políticas públicas de la Administración Pública, dirigidas a los sujetos de gestión estatales y privados. ${ }^{34}$

Sanz Larruga considera en este análisis que

paralelamente al extraordinario progreso científico y tecnológico que ha permitido un alto nivel de vida en las sociedades desarrolladas hoy, más que nunca, se advierten los innumerables riesgos originados por el propio desarrollo tecnológico y sobre los que, pese a dicho progreso, sigue existiendo una considerable incertidumbre científica sobre sus efectos sobre el medio ambiente y la salud humana. ${ }^{35}$

Son elementos que permiten ponderar que las acciones y estrategias en las formas de gestión han evolucionado, están dirigidas a la obtención de la sostenibilidad ambiental, pero aún adolecen de un balance integrador de manera adecuada de los resultados económicos, ambientales y sociales, donde estén presente los procesos de la Administración Estratégica, al constituir estos una herramienta de gestión que guiará al administrador con una visión

33 A. Antúnez Sánchez, "La empresa de alta tecnología”, Revista Fórum Administrativo, n. ${ }^{\circ} 189$ (2016); M. Moreno, Politicas públicas para el desarrollo de la ciencia, la tecnología y la innovación. Una mirada desde el contexto cubano actual. El derecho público en perspectiva (La Habana: UNIJURIS, 2016).

34 A. Antúnez Sánchez, "El tratamiento jurídico de la etiqueta-certificación ambiental. Regulación en el derecho cubano", Revista Iberoamericana de Derecho Ambiental y los Recursos Naturales, n. ${ }^{\circ} 18$ (2015).

35 F. Sanz Larruga, "Sostenibilidad ambiental y derecho administrativo: ¿̨nuevo remedio ante la crisis económica o una exigencia constitucional? A propósito de la nueva Ley de Economía Sostenible”, VI Congreso de la Asociación de profesores de Derecho Administrativo, Palma de Mallorca, 2011. 
clara y precisa de su negocio, o mejor, de su ámbito de actuación. Ello nos dice que necesario incentivar su desarrollo y análisis considerando sus beneficios, al ser una herramienta que permite brindar una comunicación clara y abierta, permita identificar anticipadamente los posibles riesgos a los que se puedan exponer la forma de gestión e identificar las brechas que les admita diseñar la estrategia de gestión adecuada. Para ello, el fomento como institución jurídica del derecho administrativo ambiental es un elemento a ponderarse, vinculada a los principios que desde el derecho ambiental informan como el de precaución y el de prevención. ${ }^{36}$

\section{LA FÓRMULA ESTIMULACIÓN/RECOMPENSA EN EL DERECHO AD- MINISTRATIVO AMBIENTAL}

La auditoría ambiental está concebida como parte de la formula estímulo/recompensa, al alentar el cumplimiento de la normativa ambientalista por los sujetos de gestión económica en espera de un beneficio de su ejecución, fomentado por la autorregulación, basado en los esquemas de comando y control, y siendo la herramienta de gestión clave para el desarrollo sostenible y el acatamiento de la normativa ambiental, además de ser apreciado con el fomento de los mercados verdes y a la empresa que implementa tecnologías limpias o ecológicas. A estas normas técnicas ambientales les ocurre como al derecho ambiental: están mutando, se señala un mayor protagonismo de la gestión ambiental en los procesos de planificación estratégica de la organización, con un incremento en el enfoque del liderazgo dentro de la Administración Estratégica, además de las iniciativas proactivas para proteger el medio ambiente de los daños y la degradación, tales como el uso sostenible de los recursos y la mitigación del cambio climático, la adición de una estrategia de comunicación, entre muchos cambios. $^{37}$

Por consiguiente, la Administración Pública en su gestión implementa técnicas de fomento, que se caracterizan por el respeto de la libertad de los destinatarios; también, la Administración estimula la actuación de estos de acuerdo con los intereses generales al proponerles incentivos — normalmente económicos (subvenciones) — que le faciliten esa actuación protectora al medio ambiente. Las técnicas son variadas, pero en el ámbito del medio ambiente se limitan a ayudas económicas; también aparecen las ecoauditorías y la implementación de las ecoetiquetas como herramientas de mercado dentro de esta fórmula estimulación/ recompensa.

36 A. Antúnez Sánchez, "Los principios del derecho ambiental que informan la auditoría ambiental en su aplicación por la Entidad Fiscalizadora Superior en Cuba”, De Jure, n. ${ }^{\circ} 1$ (2015).

37 La revisión se lleva a cabo por un comité técnico de la ISO denominado ISO/TC 207/SC 1, compuesto por expertos designados por sus organismos nacionales de acreditación y las organizaciones de enlace. En https://committee.iso.org/ sites/tc207sc1/home/projects/ongoing/iso-14001-revision.html 
Fernández de Gatta Sánchez, refiere que

a causa de la creciente degradación del medio ambiente ha traído consigo que las empresas e industrias comiencen a utilizar nuevos instrumentos de protección ambiental, aunque sean de carácter voluntario, en el contexto de una nueva ética empresarial. Desde hace algunos años surge el concepto de RSC para referirse al proceso mediante el cual dichas empresas deciden voluntariamente contribuir al logro de una sociedad mejor y de un medio ambiente más limpio. Junto a esta línea de actuación, han surgido otros instrumentos que, asimismo, deben integrarse en esta nueva ética empresarial. ${ }^{38}$

Parejo Alfonso reseña que

actualmente vivimos en una época de cierta preocupación política, institucional y privada por la situación del medio ambiente. La valoración social de las cuestiones ambientales ha cambiado profundamente en las últimas décadas del siglo XX y los primeros ańos del siglo XXI, en general hacia posiciones de una mayor concienciación por la calidad del medio ambiente, ante la eventual sexta extinción que se avecina y cuyo culpable son las conductas inadecuadas originadas por el hombre. ${ }^{39}$

Estos elementos abordados son una respuesta a lo aprobado en la Declaración sobre Desarrollo Sostenible en el 2002 ${ }^{40}$ como lo señalara Martín Mateo, ${ }^{41}$ al decir que este es el megaprincipio del derecho ambiental; se señala que el sector privado (incluidas las grandes empresas y las pequeńas) tiene el deber de contribuir a la evolución de comunidades y sociedades equitativas y sostenibles (Principio 24), y que las empresas del sector privado deben cumplir la obligación de rendir cuentas, en un entorno reglamentario, transparente y estable (Principio 26).

En el Plan de Acción aprobado en la Cumbre Mundial, se aprecia cómo se hace un llamamiento al mundo empresarial a tomar medidas voluntarias que mejoren su impacto social y medioambiental, mediante sistemas de gestión ambiental, códigos de conducta, certificaciones y comunicación pública de los aspectos sociales y ambientales, como lo acordado también en Francia 2015, en relación con el cambio climático. ${ }^{42}$ Este nuevo paradigma ambientalista implica a la empresa no solo como actor comercial sino también como actor social; en tal sentido, ello impulsa a modificar la actitud seguida por el capitalismo en esa cara de reducción de la vida a las actividades económicas y de reemplazo del lugar del ciudadano por el del con-

38 D. Fernández de Gatta Sánchez, "La responsabilidad social corporativa en materia ambiental. Estado de la cuestión”, Boletín económico ICE, $\mathrm{n} .^{\circ} 2824$ (2004).

39 L. Parejo Alfonso, El derecho ante la innovación y los riesgos derivados del cambio climático (España: Tirant lo Blanch, 2015).

40 Declaración de Johannesburgo sobre el desarrollo sostenible, ONU, 2002.

41 Véase R. Martín Mateo, Tratado de derecho ambiental. Primera edición (España: Trivium, 1991).

42 Convención sobre el Cambio Climático, París, ONU, 2015. 
sumidor o un simple componente de la producción, sino que como sujeto económico actúe como un factor de cambio. Por el contrario, las nuevas tendencias abordan la problemática actual de las incidencias en la sociedad por las actividades empresariales que afectan tanto al medio ambiente como a los trabajadores de las mismas, creando una conciencia universal que va más allá de intereses particulares (PyMES) o sectoriales, tal y como lo ponderan Brañes Ballesteros, Lorenzetti y Bellorio Clabot. ${ }^{43}$

Autores desde la doctrina administrativa ambientalista de la Unión Europea que han abordado este tema, como Martín Mateo, Sanz Rubiales, Betancor Rodríguez, significan en sus consideraciones que en la Unión Europea desde el pasado siglo son del criterio que la etiqueta ambiental está vinculada al derecho del consumidor ${ }^{44}$ y es un tema pertinente en los sujetos de gestión; para ello fue creado un programa para una política de protección e información de los consumidores, a partir de la premisa de que el consumidor ya no podía ser considerado únicamente como un comprador y usuario de bienes y servicios, para uso personal, familiar o colectivo, sino como una persona interesada en los diferentes aspectos de la vida social que como consumidor puedan afectarle directa o indirectamente. Coinciden en que se ha operado una cierta universalización de los intereses del consumidor que escapan a los meros elementos contractuales que regulan la adquisición final de bienes y servicios. Consideran estos autores consultados, que constituye una declaración técnica de que un producto reúne determinadas cualidades ambientales y una autorización para poder ostentar en su comercialización un determinado distintivo. En esta misma vía se aprecia cómo se inscribe dentro de las medidas de integración del medio ambiente en el mercado, que no son las tradicionales medidas administrativas de reglamentación, inspección, autorización y sanción.

Ello permite reconocer como en el siglo XXI se valora que la demanda de productos y servicios ecológicos parece haber establecido un nicho o segmento de mercado especializado. Si bien los mercados con etiquetado ecológico parecen haberse estabilizado o nivelado, tanto la etiqueta-certificación ambiental como la adquisición de productos ecológicos están en plena expansión como política de fomento por la Administración Pública entre los instrumentos de carácter cooperador para el modelo de América del Sur, el de la Unión Europea y algunas naciones en Centroamérica. Con ello se permite proteger la salud humana y a la naturaleza.

43 Véase para ello, para profundizar, R. Brañes Ballesteros, Informe del derecho ambiental en Latinoamérica, análisis histórico-doctrinal y jurídico desde el derecho ambiental. Primera edición (PNUMA, 2001), 9-114; R. L. Lorenzetti, El paradigma ambiental (Argentina: Ministerio de la Corte Suprema, 2011); D. Bellorio Clabot, El nuevo paradigma ambiental y juridico. V Foro ambiental Internacional (Argentina, 2013), 1-24.

44 Consúltese, para profundizar, R. Martín Mateo, El etiquetado ecológico, nuevo instrumento para la tutela ambiental (España: Trivium, 1994); I. Sanz Rubiales, Sobre la naturaleza jurídica de la etiqueta ecológica (España: Marcial Pons, 2000), 7-19; M. Mora Ruiz, "Tendencias del derecho administrativo. El derecho administrativo ambiental: transformaciones en el derecho administrativo general", Revista Derecho y Conocimiento (2012); A. Betancor Rodríguez y C. Larrinaga González, EMAS: análisis, experiencias e implantación (Madrid: ECOIURIS, 2004), 77. 
Las etiquetas, las certificaciones y las adquisiciones son catalogadas como categorías únicas, vinculadas entre sí, pero necesitadas de una mirada con una dimensión ambiental con la aplicación de la RSE por los sujetos de gestión. También, reconocidas en la doctrina del derecho administrativo ambiental como técnicas de fomento y de acreditación ambiental dentro de la fórmula estímulo/recompensa. ${ }^{45}$

La etiqueta ambiental, como instrumento de fomento ambiental, es utilizada por la Administración Pública al ser el resultado de las políticas públicas para proteger el medio ambiente en una nación dentro de su derecho administrativo ambiental, tal y como se señalará por Martín Mateo, Mora Ruiz, Sanz Rubiales. Por ello, los empresarios dentro de las formas de gestión deben hacer estudios de mercado — marketing empresarial- para conocer si sus productos tendrán la aceptación esperada por parte de los consumidores como productos ecológicos o amigables con el ambiente, vinculada con la certificación de la empresa responsable y con el ambiente dentro de la RSE, como un valor ańadido. ${ }^{46}$

\section{VISIÓN DESDE LA ADMINISTRACIÓN ESTRATÉGICA PARA LOGRAR LA EMPRESA COMPETITIVA AL APLICAR LA FÓRMULA ESTIMULACIÓN/RE- COMPENSA}

La Administración Estratégica está considerada hoy un desafío en el siglo XXI, debido a que va mucho más allá de impartir órdenes a los miembros de la organización como sujetos económicos de gestión en los empresarios. Por lo que, aplicar la dirección estratégica en una organización depende de una serie de consideraciones, entre las cuales están el análisis de dos entornos (interno y externo) de la organización, el establecimiento de directrices organizacionales (metas y objetivos), la formulación de la estrategia (empresarial, unidad de negocio, funcional), la implementación de la estrategia y el control estratégico. El administrador del sujeto de gestión debe tener la visión de saber qué tipos de sistemas de información deberá adoptar, el cual viabilizará todas las informaciones para la toma de decisiones, con una mayor agilidad y precisión para la obtención de resultados positivos.

También, el empresario del sujeto de gestión debe saber visionar qué tipos de sistemas de información debe adoptar, el cual viabilizaría todas las informaciones para la toma de decisio-

45 Para profundizar en este sentido, véase L. F. López Álvarez, La normalización, la certificación y las marcas de conformidad para la gestión ecológica de las empresas. Tratado de derecho ambiental (España: Editorial CEF, 2014), 654; P. Dopazo Fragio, El régimen jurídico de las marcas de calidad ambiental. Etiqueta ecológica y tutela ambiental (Madrid: Exlibris, 2001); A. Carballo Penela, Ecoetiquetado de bienes y servicios para un desarrollo sostenible (Espańa: AENOR, 2010).

46 Para profundizar, consúltese, $\mathrm{H}$. Bowen, La responsabilidad social de los empresarios. La auditoría, vínculos con otras ciencias y saberes (Estados Unidos de América, 1953); D. Fernández de Gatta Sánchez, "La responsabilidad social corporativa en materia ambiental. Estado de la cuestión”, Boletín Económico ICE, n. 2824 (2004); A. Vives, La responsabilidad social de la empresa en América Latina (Washington: Fondo Multilateral de Inversiones, 2011); A. Antúnez Sánchez y E. Díaz Ocampo, "La responsabilidad social y medio ambiental de la empresa: una perspectiva desde Cuba", Revista Responsabilidad Social Empresarial (2017). 
nes, con una mayor agilidad y precisión para la obtención de resultados positivos. La protección del bien jurídico ambiente en el siglo XXI se exterioriza en tres dimensiones: la económica, la social y la ambiental a partir del desarrollo industrial, equilibrado para generar recursos, empleos y promover la educación ambiental como bases del bienestar social y la calidad de vida, para lograr alcanzar el principio del desarrollo sostenible con la aplicación de la RSE al conformarse la Empresa Responsable con el Ambiente. En sí, la misma está considerada como una herramienta de gestión empresarial vinculada con la implementación de la RSE dentro del sujeto de gestión económica que la aplique. Ello le proporciona una mejora de su eficacia y eficiencia organizacional. Incidentes en el equilibrio inestable de la naturaleza, el que no asegura la armonía entre los seres vivos y estos y el medio ambiente. Es el resultado de unas relaciones generalmente conflictivas entre las especies, y de la necesidad de amoldarse a las condiciones de su entorno. Equilibrio que, lejos de responder a un pacto de convivencia entre las partes intervinientes, se produce por la mejor adaptación al medio de unas especies competidoras.

No es secreto que en los últimos años la relación entre el medio ambiente, la competitividad y el intercambio comercial han estado ganando posiciones relativas debido a la rápida expansión del comercio mundial. En forma paralela, el mundo ha ido avanzando rápidamente al proceso de integración regional, incorporado a una mayor complejidad en la relación entre medio ambiente y comercio. Por su vínculo con la aplicación e implementación en los sujetos de gestión de la fórmula estimulación/recompensa se aprecia a partir de que el derecho ambiental por su carácter evolutivo a partir de su horizontalidad, o cuanto menos su transversalidad, dada su condición multidisciplinar y pluridimensional, donde los instrumentos de mercado de carácter cooperador demuestran que la evolución del derecho administrativo ambiental, donde se refuerzan los poderes de intervención en el sentido del control y de la exigencia de la responsabilidad por parte de la Administración Pública. En la gestión compartida del medio ambiente implica el modelo de gestión descentralizada, en ella hay un reparto de tareas entre la Administración Pública y los particulares. ${ }^{47}$

Ya en la segunda década del siglo XXI, se muestra que uno de los principios que está revolucionando el actuar de la Administración Pública y dentro de esta al derecho administrativo es el de participación pública, exige la participación democrática en los procedimientos decisorios sobre materias de repercusión ambiental. Es apreciado con la entrega creciente de determinadas funciones a la colaboración público-privado, que de forma tradicional la tenía asentada en su tesis de la concesión de servicios o de la concesión demanial y que hoy ha

47 En este sentido, véase para profundizar R. Martín Mateo, Derecho administrativo ambiental. Sexta edición (España: Trivium, 1997); C. Botassi, Derecho administrativo ambiental (La Plata: Editorial Platense, 1997); B. Lozano Cutanda, Manual de derecho administrativo ambiental. Tercera edición (España: Dykinson, 2003); B. Lozano Cutanda, Derecho ambiental administrativo. $11^{\mathrm{a}}$ edición (Madrid: La Ley, 2010); J. Soriano García, El derecho administrativo y los desafíos del siglo XXI (Espańa: Aranzadi, 2011); M. Mora Ruiz, La gestión ambiental compartida: función pública y mercado. Primera edición (España: Lex Nova, 2012). 
impactado a prácticamente todas las técnicas de intervención administrativa, incluyendo a la clásica autorización que hoy por hoy apenas es reconocible.

La implementación de la Administración Estratégica se considera que es uno de los retos por vencer por la Administración Pública en el actual siglo, a partir de renovar la industria con nuevas tecnologías limpias, potenciar la cultura empresarial, aplicar las herramientas de mercado, actualizar los ordenamientos jurídicos en el derecho de la empresa, el derecho del consumo, de la contaminación industrial, del fomento ambiental, de la biodiversidad, de aguas, de la salud, forestal, de minas y la materia penal ambiental. Todos estos elementos deben ser implementado a partir de una gestión estratégica por el sujeto de gestión, que permita con ello combinar las actividades de varias áreas funcionales de una organización para lograr los objetivos organizacionales que se propongan, en el caso ponderar la dimensión ambiental, para alcanzar la calidad ambiental. Para ello debe existir la confluencia de una adecuada planificación presupuestaria, una planificación estratégica y una gestión estratégica. ${ }^{48}$

Ello permitirá que los sujetos de gestión puedan mostrar sus resultados productivos con competitividad empresarial, donde el medio ambiente toma relevancia. Es así como la competitividad de una empresa, definida como la capacidad que poseen las firmas para mantener o aumentar cuota de mercado en forma sostenida o como la capacidad que poseen las empresas para disminuir los costos y ofrecer productos de alta calidad a un precio favorable, está influenciada por la variable ambiental. En este contexto, al aparecer la Administración Estratégica, y dentro de ella el control estratégico se puede medir el desempeño organizacional, comparándolo con las metas y patrones, y tomar las acciones correctivas necesarias. En este sentido está la dimensión ambiental como parte de los objetivos organizacionales con inteligencia. Toda vez que es pertinente para una empresa prever lo que podría suceder en el medio ambiente y analizar los posibles efectos, cualitativos y cuantitativos, de las medidas preventivas y curativas anticontaminantes de largo plazo. Por ello es que se considera que la dirección estratégica es un elemento a ponderarse en las formas de gestión económicas, aplicando para ello la inteligencia ecológica. ${ }^{49}$

También se aprecia que hoy las empresas perciben el tema ambiental no simplemente como una función de control de entes externos, sino como un área en la que se deben llevar a cabo innovaciones estratégicas, en especial cuando se refiere a empresas exportadoras, donde

48 Véase para profundizar en este sentido, R. Lurbé, "Gestión estratégica. Navegando hacia el cuarto paradigma”, Contribuciones a la Economía (2013); T. J. Betancourt, Gestión estratégica. Navegando hacia el cuarto paradigma. Tercera edición (2003); D. Fred, Administración estratégica. 11 a edición (Estados Unidos de América: Person Education, 2008).

49 D. Goleman, Inteligencia ecológica (Barcelona: Kairos, 2010); J. A. Del Brío González y B. Junquera Cimadevilla, Medio ambiente y empresa: de la confrontación a la oportunidad. Biblioteca Civitas Economía y Empresa. Colección Empresa (Madrid, 2001), 21-39; C. Fussler y P. James, Eco-innovación. Integrando el medio ambiente en la empresa del futuro (Madrid: Mundi-Prensa, 1999), 59-67. 
sus mercados poseen restricciones ambientales no solo respecto a la calidad de los productos y embalaje, sino también respecto a los procesos productivos, donde se pondera la calidad ambiental. Para ello, el objetivo del desarrollo sostenible es un gran reto y a la vez una gran oportunidad tanto para los Gobiernos como para los empresarios tanto estatales como privados. Se puede afirmar entonces que el medio ambiente ha pasado de ser un factor ajeno a las empresas como sujetos de gestión, y ha pasado a convertirse en un factor de competitividad, cuando se plantean estrategias de prevención y reducción de residuos y emisiones, al transformarse en reducciones de costos o en la generación de productos alternativos a partir de los residuos. Esto un buen empresario lo tiene que tener en su visión estratégica y trazarse metas para su control, para poder competir en lo que se ha denominado mercado verde ${ }^{50}$ a nivel internacional, donde se ha incrementado en gran medida la participación del mercado de los productos orgánicos, y donde el sujeto de gestión que no pondere las herramientas de mercado no será una empresa competitiva.

La pregunta clave a responder es ¿qué clase de desarrollo se podrá adoptar y qué modelo de empresa tendríamos que poner en marcha que no destruyera la naturaleza, que no dañe la salud física ni mental de las personas y que nos permita desarrollarnos económica y técnicamente pero también personal y espiritualmente? La respuesta nos lleva ineludiblemente hacia el desarrollo sostenible. ${ }^{51}$

\section{COROLARIO}

- La preocupación ambiental y ética de las empresas como sujetos de gestión de acuerdo con las tendencias de las sociedades no son nuevas, si bien han tomado auge desde los años 90' del siglo XX; en el siglo XXI, la protección del bien jurídico ambiente en el siglo XXI se exterioriza en tres dimensiones: la económica, la social y la ambiental a partir del desarrollo industrial, equilibrado para generar recursos, empleos y promover la educación ambiental como bases del bienestar social y la calidad de vida, para lograr el principio del desarrollo sostenible con la aplicación de la RSE al conformarse la Empresa Responsable con el ambiente y tributar al alcance del desarrollo sostenible.

- Los instrumentos de mercado de carácter cooperador como fórmula estímulo/recompensa para los sujetos de gestión, demuestran que la evolución del derecho administrativo ambiental refuerza los poderes de intervención en el sentido del control y la exigencia de la

50 Los mercados verdes son mercados de productos y servicios ambientalmente amigables y de aquellos derivados del aprovechamiento sostenible del medio ambiente. Aparecen como una alternativa al mercado convencional, saturado de productos con ingredientes contaminantes que cada vez más van siendo de menor preferencia por los consumidores.

51 Para una profundización sobre esta cuestión véase, J. C. Alli Aranguren, "Del desarrollo sostenible a la sostenibilidad. Pensar globalmente y actuar localmente”, Revista de Derecho Urbanistico y Medio ambiente, n. 226 (2006); D. Loperena Rota, Desarrollo sostenible y globalización (Argentina: Thomson-Aranzadi, 2003). 
responsabilidad por parte de la Administración Pública. La gestión ambiental compartida del medio ambiente implica el modelo de gestión descentralizada, hay un reparto de tareas entre la Administración y los particulares en pos de lograr el desarrollo sostenible.

- Los retos por vencer por la Administración Pública en el siglo XXI como parte de la Administración Estratégica en la dirección por objetivos desde la dimensión ambientalista serían: renovar la industria con nuevas tecnologías limpias, potenciar una cultura empresarial, actualizar los ordenamientos jurídicos a partir del derecho de la empresa, del derecho del consumo, de la contaminación industrial, del fomento ambiental, de la biodiversidad, de aguas, de la salud, forestal, de minas y del penal. Se hace necesario definir la política tecnológica para reorientar el desarrollo industrial, el control de las tecnologías en uso, a fin de promover la modernización en atención a la eficiencia energética, la eficacia productiva y el impacto ambiental para elevar la soberanía tecnológica en la actualización de su modelo económico, implementadas en la contratación pública al ponderar las normas técnicas ambientales.

- El sumak kawsay y la pachamama, como formas de vida en armonía con la naturaleza y con otros seres humanos, son conceptos que representan la aspiración de muchos pueblos desde el Abya-Yala. La nación ecuatoriana como referente es un concepto jurídico en construcción, cuyo origen tiene su génesis en el derecho consuetudinario de los pueblos originarios, como reconocimiento de los derechos ambientales dentro del pluralismo jurídico De Jure.

\section{REFERENCIAS}

- Agencia Nacional de la Calidad y Evaluación. Libro Blanco. Ciencias ambientales. España: Agencia Nacional de la Calidad y Evaluación, 2004.

- Alli Aranguren, J. C. "Del desarrollo sostenible a la sostenibilidad. Pensar globalmente y actuar localmente". Revista de Derecho Urbanistico y Medio ambiente, n. ${ }^{\circ} 226$ (2006).

- Antúnez Sánchez, A. "Los principios del derecho ambiental que informan la auditoría ambiental en su aplicación por la Entidad Fiscalizadora Superior en Cuba”. De Jure, n. ${ }^{\circ} 1$ (2015).

"El tratamiento jurídico de la etiqueta-certificación ambiental. Regulación en el derecho cubano". Revista Iberoamericana de Derecho Ambiental y los Recursos Naturales, n. ${ }^{\circ}$ 18 (2015).

“La empresa de alta tecnología”. Revista Fórum Administrativo, n. ${ }^{\circ} 189$ (2016). 
- A. Antúnez Sánchez y E. Díaz Ocampo. "La responsabilidad social y medio ambiental de la empresa: una perspectiva desde Cuba". Revista Responsabilidad Social Empresarial (2017).

“El pluralismo jurídico en América Latina”. Dos Tribunais, n. 990 (2018).

- Beck, U. Políticas ecológicas en la edad del riesgo. Antídotos. Responsabilidad organizada. Barcelona: El Roure, 1998.

- Beck, U. La sociedad del riesgo. Hacia una nueva modernidad. Barcelona: Paidós Ibérica, 1998.

- Bellorio Clabot, D. El nuevo paradigma ambiental y jurídico. V Foro ambiental Internacional. Argentina, 2013.

- Bengoechea Morancho, A. Dimensión medioambiental de la responsabilidad social corporativa. La Coruña: Netbiblo, 2010.

- Bermejo Vera, J. Derecho administrativo. Parte especial. Madrid: Civitas, 1994.

- Betancor Rodríguez, A. y C. Larrinaga González. EMAS: análisis, experiencias e implantación. Madrid: ECOIURIS, 2004.

- Betancourt, T. J. Gestión estratégica. Navegando hacia el cuarto paradigma. Tercera edición. 2003.

- Botassi, C. Derecho administrativo ambiental. La Plata: Editorial Platense, 1997.

- Bowen, H. La responsabilidad social de los empresarios. La auditoría, vinculos con otras ciencias y saberes. Estados Unidos de América, 1953.

- Brañes, R. Manual de derecho ambiental mexicano. México: Fondo de Cultura Económica, 1994.

- Brañes Ballesteros, R. Informe del derecho ambiental en Latinoamérica, análisis histórico-doctrinal y juridico desde el derecho ambiental. Primera edición. PNUMA, 2001.

- Callejón, M. "I+D, innovación y política pública: hacia una nueva política económica de innovación". Revista sobre la Sociedad del Conocimiento, n. ${ }^{\circ} 4$ (2007).

- Carballeira Rivera, M. T. "El cambio climático. Análisis científico y jurídico del problema de la emisión de gases de efecto invernadero". Revista de Derecho Urbanistico y Medio Ambiente, n. 156 (1997): 161-186.

- Carballo Penela, A. Ecoetiquetado de bienes y servicios para un desarrollo sostenible. Espańa: AENOR, 2010. 
- Comisión de las Comunidades Europeas. Libro Verde. Fomentar un marco europeo para la responsabilidad social de las empresas. Bruselas: Comisión de las Comunidades Europeas, 2003.

- Comisión Mundial del Medio Ambiente y del Desarrollo. Nuestro futuro común. España: Editorial Alianza, 1988.

- Darnaculleta Gardella, M. Autorregulación y derecho público: la autorregulación regulada. Barcelona: Marcial Pons, 2005.

- Del Brío González, J. A. y B. Junquera Cimadevilla. Medio ambiente y empresa: de la confrontación a la oportunidad. Biblioteca Civitas Economía y Empresa. Colección Empresa (Madrid, 2001).

- Dopazo Fragio, P. El régimen jurídico de las marcas de calidad ambiental. Etiqueta ecológica y tutela ambiental. Madrid: Exlibris, 2001.

- Embid Irujo, A. Agua, energía, cambio climático y otros estudios de derecho ambiental. Primera edición. España: Aranzadi, 2015.

- Esteve Pardo, J. Técnica, riesgo y derecho. Tratamiento del riesgo tecnológico en el derecho ambiental. Barcelona: Ariel, 1999.

—Autorregulación, génesis y efectos. Espańa: Editorial Aranzadi, 2002.

2014.

- Fernández de Gatta Sánchez, D. "La responsabilidad social corporativa en materia ambiental. Estado de la cuestión”. Boletín económico ICE, n. 2824 (2004).

- Fernández de Gatta Sánchez, D. Sistema juridico-administrativo de protección del medio ambiente. Tercera edición. Espańa: Ratio Legis, 2014.

- Fred, D. Administración estratégica. $11^{\mathrm{a}}$ edición. Estados Unidos de América: Person Education, 2008.

- Freire, P. Pedagogía de la autonomía. Saberes necesarios para la práctica educativa. Undécima edición en español. Argentina: Siglo XXI, Argentina, 2006.

- Fussler, C. y P. James. Eco-innovación. Integrando el medio ambiente en la empresa del futuro. Madrid: Mundi-Prensa, 1999.

- García de Enterría E. y L. Parejo Alfonso. Lecciones de derecho urbanístico. España: Editorial Civitas, 1981.

- Goleman, D. Inteligencia ecológica. Barcelona: Kairos, 2010. 
- Granja Arce, H. "Nuevos riesgos ambientales y derecho administrativo". Tesis de maestría. Colegio Mayor Nuestra Señora del Rosario, 2010.

- Gray, R.; J. Bebbington y D. Walters. Contabilidad y auditoría ambiental. Bogotá: Ecoe Ediciones, 1999.

- Guzmán Aguilera, P. Introducción al análisis económico del derecho ambiental. Primera edición. Bogotá: Universidad Externado de Colombia, 2006.

- Hallegatte, S. "Economic Resilience, Definition and Measurement". Policy Research Working Paper, n. ${ }^{\circ} 6852$ (2014).

- Harlem Burtland, G. Nuestro futuro común. ONU: Estados Unidos de América, 1984.

- Jordano Fraga, J. La protección del derecho a un medio ambiente adecuado. Barcelona: J.M. Bosch, 1995.

- Juste Ruiz, J. Derecho internacional del medio ambiente. Madrid: McGraw-Hill, Madrid, 1999.

La evolución del derecho internacional del medio ambiente. España: Universidad de Valencia, 2007.

- Kuznets, S. Modern Economic Growth: Rate, Structure, and Spread (El crecimiento económico moderno: tasas, estructura y margen). New Haven y Londres: Yale University Press, 1996.

- Leff, Enrique. Los derechos del ser colectivo y la reapropiación social de la naturaleza: a guisa de prólogo a Justicia ambiental: construcción y defensa de los nuevos derechos ambientales, culturales y colectivos en América Latina, de Enrique Leff. México D.F.: PNUMA/ CEIICH-Unam, 2001.

- Llasag Fernández, R. Los derechos de la naturaleza y la naturaleza de sus derechos. Quito: Ministerio de Justicia y Derechos Humanos, 2011.

- Loperena Rota, D. El derecho al medio ambiente adecuado. Madrid: Civitas, 1996. Desarrollo sostenible y globalización. Argentina: Thomson-Aranzadi, 2003.

- López Álvarez, L. F. La normalización, la certificación y las marcas de conformidad para la gestión ecológica de las empresas. Tratado de derecho ambiental. España: Editorial CEF, 2014.

- Lorenzetti, R. L. El paradigma ambiental. Argentina: Ministerio de la Corte Suprema, 2011.

- Lozano Cutanda, B. Manual de derecho administrativo ambiental. Tercera edición. España: Dykinson, 2003.

Derecho ambiental administrativo. 11 $1^{\text {a }}$ edición. Madrid: La Ley, 2010. 
- Ludevid, M. La gestión ambiental de la empresa. Barcelona: Ariel, 2000.

- Lurbé, R. "Gestión estratégica. Navegando hacia el cuarto paradigma”. Contribuciones a la Economia (2013).

- Martín Mateo, R. Tratado de derecho ambiental. Primera edición. España: Trivium, 1991. El etiquetado ecológico, nuevo instrumento para la tutela ambiental. España: Trivium, 1994.

Derecho administrativo ambiental. Sexta edición. España: Trivium, 1997.

- Mora Ruiz, M. "Tendencias del derecho administrativo. El derecho administrativo ambiental: transformaciones en el derecho administrativo general". Revista Derecho y Conocimiento (2012).

- Mora Ruiz, M. La gestión ambiental compartida: función pública y mercado. Primera edición. Espańa: Lex Nova, 2012.

- Moreno, M. Políticas públicas para el desarrollo de la ciencia, la tecnología y la innovación. Una mirada desde el contexto cubano actual. El derecho público en perspectiva. La Habana: UNIJURIS, 2016.

- Nogueira López, A. "Ecoauditorías, intervención pública ambiental y autocontrol empresarial”. Revista Aragonesa de Administración Pública, n. ${ }^{\circ} 12$ (2000): 61-96.

"Hacia un EMAS de alcance internacional en competencia con la ISO 14001: notas a la revisión del Reglamento EMAS”. Revista Actualidad Jurídica Ambiental (2010).

- Parejo Alfonso, L. El derecho ante la innovación y los riesgos derivados del cambio climático. España: Tirant lo Blanch, 2015.

- Pérez Luño, A. El desbordamiento de las fuentes del derecho. Sevilla: Real Academia Sevillana de Legislación y Jurisprudencia, 1993.

La tercera generación de derechos humanos. Pamplona: Thomson Aranzadi, 2006. Derechos humanos, Estado de derecho y Constitución. Madrid: Tecnos, 2010.

- Popoff, F. "Contabilidad de costos ambientales, un nuevo paradigma para la industria”. Revista Ambiente y Desarrollo (2013).

- Quirola Suárez, D. Sumak Kaway. Hacia un nuevo pacto social en armonía con la naturaleza. Quito: Abya-Yala, 2009.

- Real Ferrer, G. "La construcción del derecho ambiental". Revista Aranzadi de Derecho Ambiental, n. ${ }^{\circ} 1$ (2002): 76-80. 
- Rodríguez Font, M. Régimen de comunicación e intervención ambiental. Entre la simplificación administrativa y la autorregulación. España: Atelier, 2003.

- Rodríguez-Campos González, S. "El fomento de la ecoauditoría como estrategia interventora”. Revista Española de Derecho Administrativo, n. ${ }^{\circ} 119$ (2003).

- Rodríguez Salazar, A. "Teoría y práctica del buen vivir: orígenes, debates conceptuales y conflictos sociales. El caso de Ecuador”. Tesis doctoral. Universidad del País Vasco, 2016.

- Ruiz Vieytez, E. J. El derecho al ambiente como derecho de participación. Zarautz: Ararteko, 1990.

- Sanz Larruga, F. "Sostenibilidad ambiental y derecho administrativo: ¿nuevo remedio ante la crisis económica o una exigencia constitucional? A propósito de la nueva Ley de Economía Sostenible". VI Congreso de la Asociación de profesores de Derecho Administrativo. Palma de Mallorca, 2011.

- Sanz Rubiales, I. Sobre la naturaleza jurídica de la etiqueta ecológica. España: Marcial Pons, 2000 .

Cambio climático y Unión Europea: presente y futuro del mercado europeo de emisiones. España: Tirant Lo Blanch, 2014.

- Simón Yarza, F. Medio ambiente y derechos fundamentales. Madrid: Centro de Estudios Políticos y Constitucionales, 2012.

- Soler Tormo, I. "La configuración constitucional del medio ambiente como derecho". Tesis doctoral. Universidad de Valencia, 2016.

- Soriano García, J. El derecho administrativo y los desafios del siglo XXI. España: Aranzadi, 2011.

- UNESCO. Educación para todos en 2015. ¿Alcanzaremos la meta? Panorama Regional América Latina y el Caribe. París, 2008.

- Vega, F. "El buen vivir sumak kawsay en la Constitución y en el PNBV 2013-2017 del Ecuador". OBETS, n. 1 (2014).

- Vives, A. La responsabilidad social de la empresa en América Latina. Washington: Fondo Multilateral de Inversiones, 2011.

- Villavella Armengol, C. El derecho constitucional del siglo XXI en Latinoamérica: un cambio de paradigma. Estudios sobre el nuevo constitucionalismo latinoamericano. Valencia: Tirant lo Blanch, 2012.

Recibido: 23/03/2018

Aprobado: 30/04/ 2018 